\title{
Cloning, characterization and expression analysis of a novel gene encoding Kunitz-type protease inhibitor from Dolichos biflorus
}

\author{
Kalika Kuhar · Rekha Kansal • Amit Mishra • \\ Kirpa Ram Koundal · Vijay Kumar Gupta
}

Received: 27 July 2011 / Accepted: 31 January 2012/Published online: 24 March 2012

(c) The Author(s) 2012. This article is published with open access at Springerlink.com

\begin{abstract}
This paper reports the presence of a Kunitztype protease inhibitor (HGPI) gene in Dolichos biflorus for the first time. A full-length protease inhibitor gene with complete open reading frame of $669 \mathrm{bp}$ encoding 222 amino acids was cloned from $D$. biflorus using a PCRbased method. BlastN search showed that the HGPI gene shared $100 \%$ homology with Cicer arietinum trypsin inhibitor mRNA and $97 \%$ with Cajanus cajan protease inhibitor. The deduced amino acid sequence exhibited homology with Kunitz-type trypsin inhibitor from chickpea, pigeon pea and soybean. The deduced amino acid sequence contained $\mathrm{N}$-terminal signal sequence of 18 amino acids and had a molecular weight of $24 \mathrm{kDa}$. The phylogenetic tree also showed close relationship with Cicer arietinum and Cajanus cajan. Southern blotting revealed the presence of only one copy of HGPI gene in the $D$. biflorus genome. Homology modeling was employed to predict secondary structure and 3D-structural models for the protease inhibitor. The gene was found to be constitutively expressed in different tissues as determined by semi-quantitative RT-PCR. The novel HGPI gene has been submitted to the GenBank with Accession No. FN666416. The isolated novel HGPI gene will broaden the pool of plant defense genes and might be an ideal choice for developing transgenic crops resistant to insect pests, as well as pathogens. In addition, it could be used as a probe for selection of insect- and pathogen-resistant genotypes.
\end{abstract}

K. Kuhar · V. K. Gupta $(\bowtie)$

Department of Biochemistry, Kurukshetra University,

Kurukshetra, Haryana, India

e-mail: vkgupta59@ rediffmail.com

R. Kansal · A. Mishra · K. R. Koundal

National Research Centre on Plant Biotechnology, Indian

Agricultural Research Institute (PUSA), New Delhi, India
Keywords Dolichos biflorus - Kunitz type · Open reading frame Polymerase chain reaction . Trypsin inhibitor

\section{Introduction}

Plant genes that protect against herbivory and pathogen attack may be useful for heterologous expression into food and fiber crops (Sardana et al. 1998). Plant protease inhibitors (PIs) have drawn attention as possible transgenes for defense in crops by blocking the growth and development of herbivorous predators through inhibiting digestive enzymes and providing protection against pathogenic fungi and bacteria through inhibiting hydrolytic enzymes, which they use to gain entry (Johnson et al. 1989). PIs are of particular interest because they are generally the product of a single gene and inhibit proteolytic enzymes of animal and fungal origin, but rarely of plant origin (Brattsten 1991; Hilder et al. 1993). A large number of plant PI genes have been isolated, cloned and sequenced (Valueva et al. 2008; Zhang et al. 2008). The gene size and coding regions of these inhibitors are small, devoid of introns (Wang et al. 2008) and comprise readily identifiable core region covering the invariant cysteine residues. The potential of PI has been demonstrated by the transfer of these genes from different sources to several plants of economic interest, resulting in transgenic plants more resistant to predation (Lingling et al. 2005; Pujol et al. 2005) and pathogens (Qu et al. 2003; Quilis et al. 2007).

Two major serine PIs, Bowman-Birk and Kunitz family, have been studied extensively in plants. PIs of BowmanBirk family have molecular weight of 8-10 kDa with seven disulfide bonds and are relatively heat stable, whereas those belonging to the Kunitz family have a molecular weight of $20-25 \mathrm{kDa}$ with two disulfide bonds (Ryan 1990). 
Variations in specificity, timing and site of expression suggest the possible involvement of PIs in different plant functions (Beuning et al. 1994).

Kunitz trypsin inhibitor genes represent one of several seed protein gene families that are highly regulated during the plant life cycle (Goldberg et al. 1989). Genetic studies indicate that a single gene is responsible for encoding a seed protein with Kunitz trypsin inhibitor activity (Orf and Hymowitz 1979). As a group, plant KTIs have extremely diverse protease targets and thus have negative effects on a broad range of phytophagous pests and pathogens. Some plant KTIs are antimicrobial, presumably via inhibition of microbial proteinases (Kim et al. 2005; Park et al. 2005). Transcript-profiling studies have shown that several KTI genes are among the most strongly induced genes after wounding and herbivory (Major and Constabel 2006).

Dolichos biflorus is one of the lesser known, unexploited legume of tropics and subtropics grown under dry land agriculture. Considering that $D$. biflorus growth has been restricted to a few specific areas, it represents a potential source of genes for insect control. There are earlier reports for the presence of Bowman-Birk PIs in D. biflorus seeds (Mehta and Simlot 1982; Sreerama et al. 1997). However, protease inhibitor of the Kunitz family from $D$. biflorus has not yet been reported. Sequence analysis of several double headed inhibitors (Odani and Ikenaka 1976) have shown that they consist of two homologous domains, each of which contains a reactive site for a proteinase, suggesting their evolution from a common single-headed ancestor which ultimately gave an indication for the presence of Kunitz-type inhibitor in D. biflorus.

In order to broaden the pool of plant defense genes and to identify new and more potent inhibitor proteins for pest control, insect-specific inhibitor proteins and their genes need to be isolated. The PCR method has proven to be a powerful tool for identification of the specific insecticidal genes carried by different leguminous plants (Gao et al. 1998; Ismanizan et al. 2010). Hence, this paper describes the isolation, cloning and characterization of a full-length gene encoding Kunitz-type protease inhibitor from $D$. biflorus using a PCR-based method. The expression of Kunitz-type protease inhibitor gene has also been analyzed in different parts of $D$. biflorus using RT-PCR. The resulting knowledge should provide novel alternatives for the control of different insects and for coping with the problem of resistance.

\section{Materials and methods}

Materials

Seeds of Dolichos biflorus L. were procured from the Department of Plant Breeding and Genetics, HPKVV,
Palampur (Himachal Pradesh), India for experimental purposes. PCR reagents, restriction enzymes and Hexalabel $^{\mathrm{TM}}$ plus DNA labeling kit were purchased from Fermentas Inc., Maryland 21076, USA. QIAquick PCR purification kit and QIAGEN Omniscript Reverse Transcriptase were obtained from QIAGEN, Hilden, Germany, whereas pGEM $^{\circledR}-\mathrm{T}$ Easy vector kit was from Promega. Thermoscript RT-PCR kit was purchased from Invitrogen Life Technologies California, USA. Primers were commercially synthesized as highly purified salt-free products by Hysel, India. All other reagents were of the finest commercial grade available.

\section{Extraction of genomic DNA and total RNA}

Total genomic DNA was isolated from 8-day-old etiolated seedlings using the CTAB method (Murray and Thompson 1980) followed by RNase treatment. Total RNA was prepared from leaves, roots, stems, pod walls, flowers and 8-day-old etiolated seedlings by $\mathrm{LiCl}$ method (Menke et al. 1996) and from freshly harvested seeds by Kansal et al. (2008). The integrity of isolated RNA was qualitatively checked by $1 \%$ formaldehyde agarose gel electrophoresis and stained with ethidium bromide (Sambrook and Russel 2001). Isolated total RNA was further used for expression analysis of the PI gene.

\section{Southern blot analysis}

Purified DNA $(5 \mu \mathrm{g})$ was completely digested with EcoRI and $\mathrm{BamHI}$ at $37{ }^{\circ} \mathrm{C}$ overnight in a total volume of $45 \mu \mathrm{l}$ and then electrophoresed on $0.8 \%$ agarose gel. The restricted sample in agarose gel was blotted onto a Hybond $\mathrm{N}^{+}$membrane (Amersham) according to the manufacturer's instructions and hybridized with radiolabeled probe of chickpea The TI gene was obtained from NRC on Plant Biotechnology, IARI, New Delhi, India. The probe was prepared by using Hexalabel ${ }^{\mathrm{TM}}$ plus DNA labeling kit (MBI, Fermentas) as per the instruction manual. Southern blot was prepared and hybridized using standard procedure (Southern 1975).

\section{Oligonucleotide PCR primers}

Different sets of gene-specific PCR primers for amplification of Kunitz-type PI gene were designed using Primer 3.0 software (http://frodo.wi.mit.edu/primer3/). The primers were selected from highly conserved regions by using a simultaneous alignment tool through computer analysis with Clustal W tool. The primers were designed from the coding region of the genes determined through Softberry software following the standard rules and analyzed using Fast PCR software for self-dimers, melting temperature 
and priming efficiency. Primer alignment specificity was checked using NCBI blast. The amplified product size was expected to be $700 \mathrm{bp}$.

PCR amplification, cloning and sequencing

PCR was carried out to amplify the coding gene of the PI from the isolated genomic DNA with gene-specific primers according to the modified protocol of Sambrook et al. (1989). Standard PCR reaction was performed in a total volume of $25 \mu$ l containing $1 \times$ PCR buffer, $1.25 \mathrm{mM}$ $\mathrm{MgCl}_{2}, 100 \mathrm{ng}$ of genomic DNA, $2.5 \mathrm{mM}$ dNTP, 1.25 units of Taq DNA polymerase and $1 \mu \mathrm{M}$ of each oligonucleotide primer. Amplification was carried out with initial denaturation at $94{ }^{\circ} \mathrm{C}$ for $3 \mathrm{~min}$ followed by 30 cycles of denaturation at $94{ }^{\circ} \mathrm{C}$ for $1 \mathrm{~min}$, annealing at $52{ }^{\circ} \mathrm{C}$ for $1 \mathrm{~min}$, and extension at $72{ }^{\circ} \mathrm{C}$ for $1 \mathrm{~min}$ with a final extension phase of $10 \mathrm{~min}$, performed on a Perkin-Elmer Cetus Instruments thermocycler. The amplified PCR product was analyzed by conventional electrophoresis using $1.2 \%(\mathrm{w} / \mathrm{v})$ agarose gels and ethidium bromide staining (Sambrook and Russel 2001). The PCR product was purified using QIAquick PCR purification kit. According to supplier standard instructions, this purified product was cloned into pGEM $^{\circledR}-\mathrm{T}$ Easy vector (Promega) and transformed into Escherichia coli DH5 $\alpha$ competent cells. The transformants were screened by white-blue selection and tested by the method of colony PCR. The colonies showing positive result were sent for sequencing, which was done at TechnoConcept, New Delhi (India). The data obtained has been submitted to EMBL nucleotide database.

In silico analysis for characterization of full-length PI gene

The vector sequence was recognized in the sequence obtained after sequencing by VecScreen program of NCBI (http://www.ncbi.nlm.nih.gov/VecScreen/VecScreen.html). Nucleotide sequence from genomic clone and its deduced amino acid sequence were identified by the NCBI BLAST program (http://blast.ncbi.nlm.nih.gov/Blast.cgi).

ORF and the number of exons and introns in the sequence were predicted using FGENESH program of Softberry web server on URL (http://linux1.softberry.com/ berry.phtml?topic $=$ fgenesh $\&$ group $=$ programs \&subgroup $=$ gfind). This tool was also used for DNA translation. Restriction map analysis of complete ORF of $D$. biflorus PI sequence was generated using software available at http:// www.nebcutter.com.

Multiple sequence alignment for deduced amino acid sequence was done on CLUSTAL W server (Thompson et al. 1994) available at www.genome.ad.jp. Nucleotide composition and the whole protein and atomic composition analysis of protein sequence were done by using BioEdit Software version 7.0.9.1. The computation of various physical and chemical parameters of protein sequence was carried out using the ProtParam package of the ExPASy web (a)

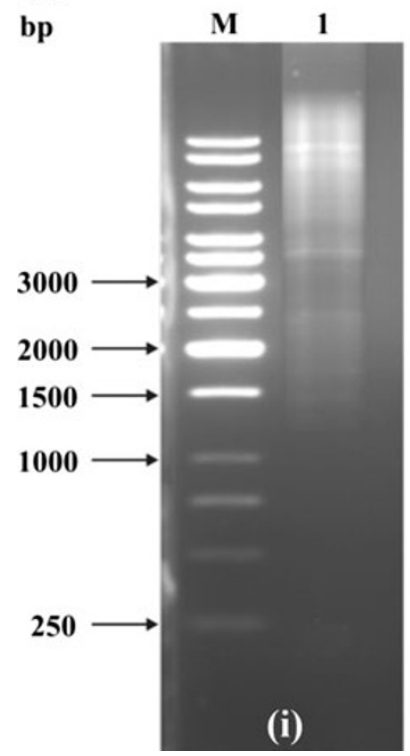

2

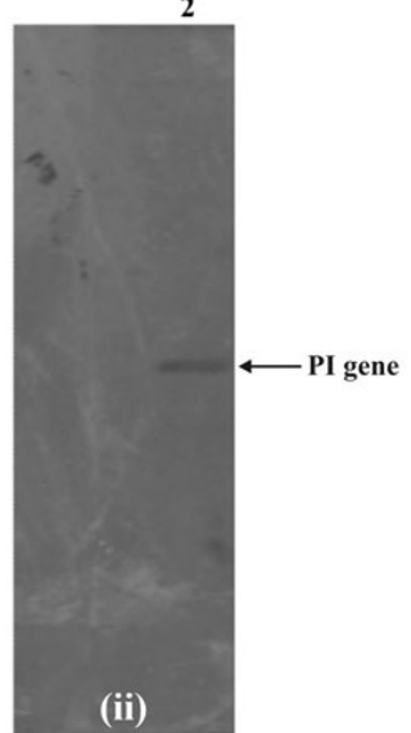

(b)

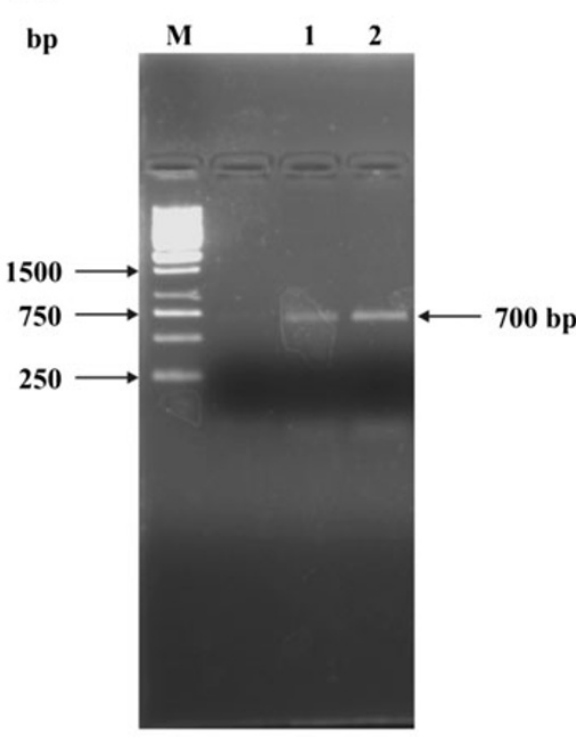

Fig. 1 a Southern blot hybridization analysis of Dolichos biflorus genomic DNA probed with chickpea trypsin inhibitor gene $i$ restriction analysis of the genomic DNA digested with EcoRI and BamHI. Lane $M 1 \mathrm{~kb}$ ladder, Lane 1 restricted genomic DNA, ii autoradiogram generated from Southern hybridization showing PI gene. b PCR amplification of full-length protease inhibitor gene from genomic DNA of Dolichos biflorus. Lane M $1 \mathrm{~kb}$ ladder, Lanes 1 and 2 fulllength PI gene 
Fig. 2 Nucleotide and deduced amino acid sequence of a genomic sequence encoding Dolichos biflorus protease inhibitor protein. The start and stop codons (underlined) are also shown
FGENESH 2.6 Prediction of potential genes in Medicago genomic DNA

Seq name: test sequence

Length of sequence: 669

Number of predicted genes 1: in +chain 1, in -chain 0 .

Number of predicted exons 1: in +chain 1, in -chain 0.

Positions of predicted genes and exons: Variant 1 from 1, Score:40.830676

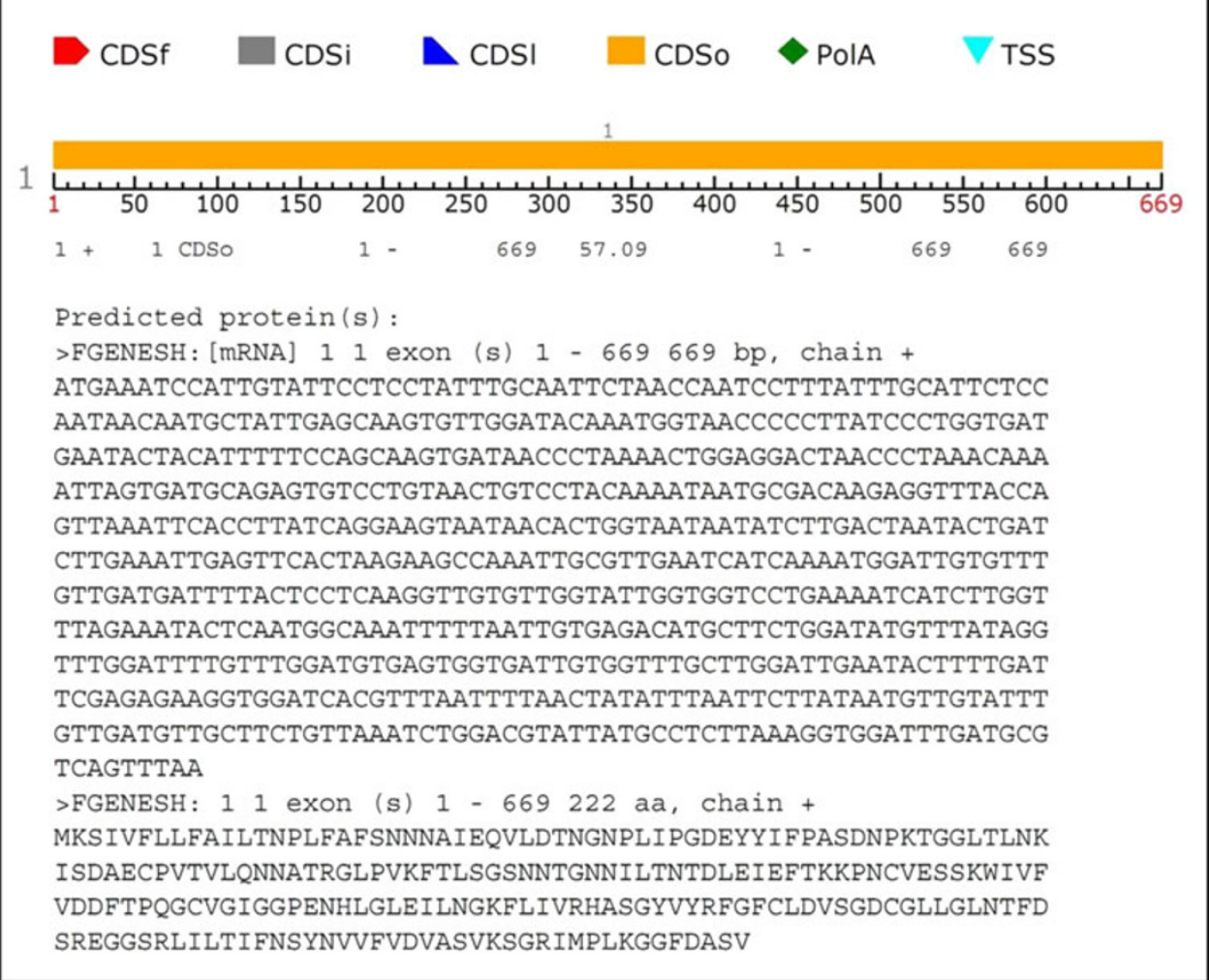

server (http://www.expasy.ch/tools/protparam.html). The exact mass of the protein sequence was deduced using the Isotopident package of the ExPASy web server (http:// education.expasy.org/studentprojects/isotopident/htdocs/). Prediction of signal peptide sequence was conducted by using SignalP package of the ExPASy web server (http:// www.cbs.dtu.dk/services/SignalP/); however, the subcellular localization of the protein was done using TargetP 1.1 tool of the ExPASy web server. The hydrophobic nature of the deduced amino acid sequence was done using ProtScale package of the ExPASy web server (http://www.expasy. ch/tools/protscale.html). The secondary structure of protein was predicted by using PSS Finder package of Softberry web server (http://linux1.softberry.com/berry.phtml?topic=pps\& group $=$ programs\&subgroup=propt $)$. The three-dimensional structure of the protein was deduced using 3Djigsaw package available on the ExPASy web server (http://bmm.cancer researchuk.org/ 3djigsaw/); however, it was visualized with the help of Rasmol package available at the ExPASy web server. The phylogenetic tree of the deduced amino acid sequence was generated using software available on http://www.123genomics.com/ along with the other PI amino acid sequences collected from GenBank. The data were used to generate a rooted tree by the neighbor joining method.

Expression analysis of the isolated protease inhibitor gene

The expression of the PI gene encoding Kunitz-type inhibitor protein in the different parts of $D$. biflorus was analyzed by RT-PCR. Total RNA $(5 \mu \mathrm{g})$ isolated from different tissues was reverse transcribed into cDNA using QIAGEN Omniscript Reverse Transcriptase as recommended by the manufacturer. The synthesized cDNA was further amplified by PI gene-specific primers using optimized PCR conditions as described above, but with $5 \mu \mathrm{l}$ cDNA instead of $1 \mu \mathrm{l}$ of genomic DNA and 25 cycles instead of 30 cycles. The amplified PCR product was separated by $1.2 \%$ agarose gel electrophoresis. 
(a)

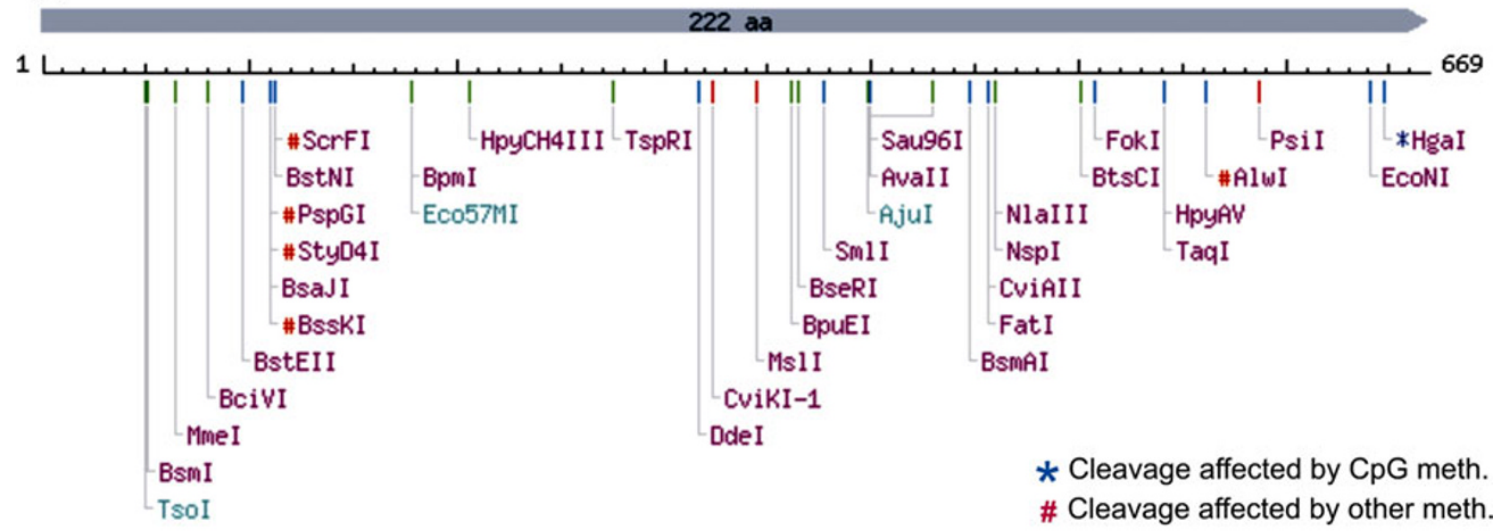

(b)

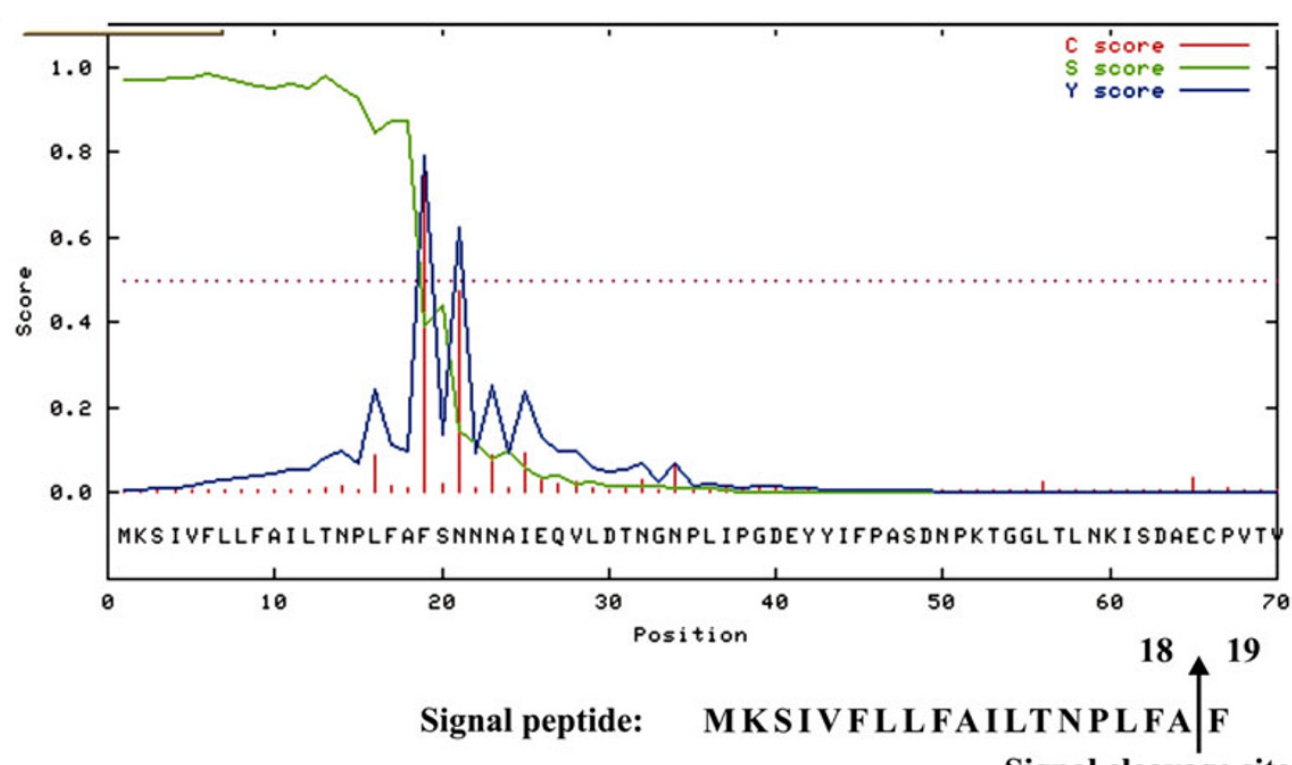

(c)

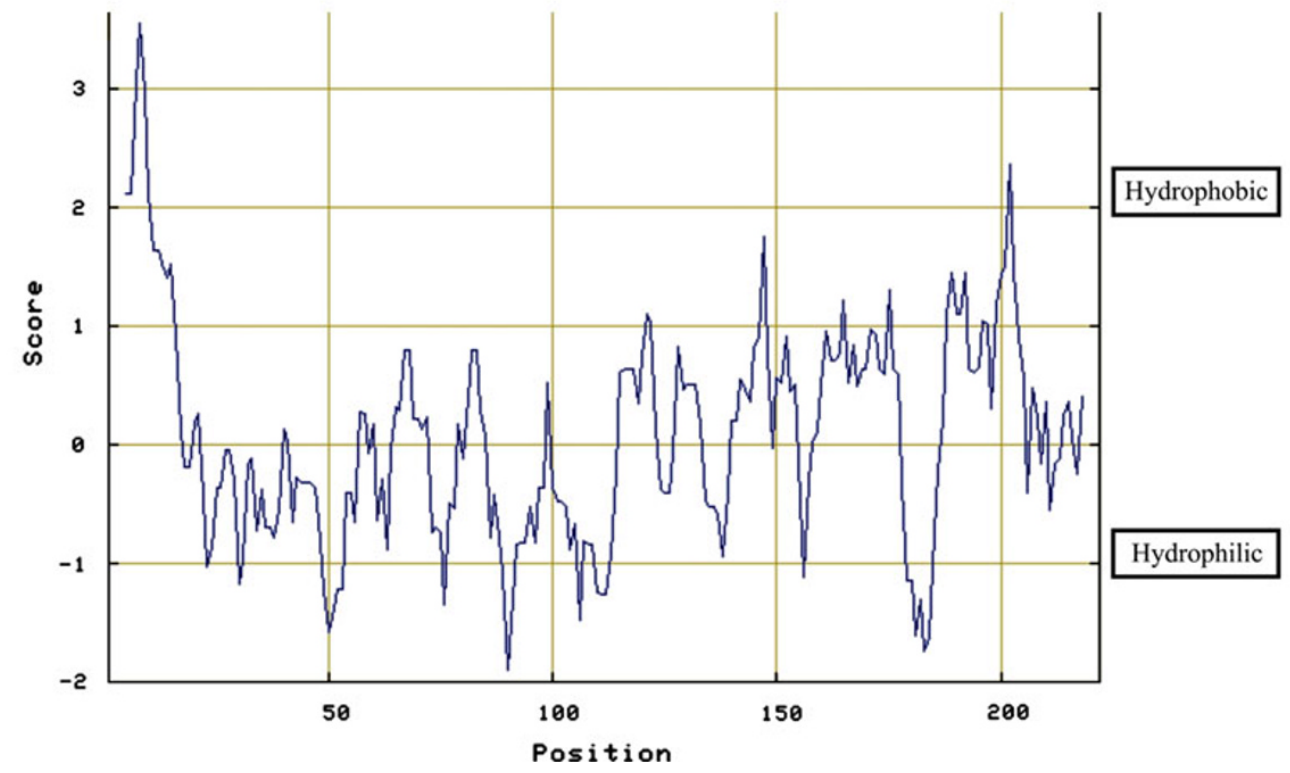

Fig. 3 a Restriction map of linear sequence encoding Dolichos biflorus protease inhibitor. b Signal peptide prediction of Dolichos biflorus protease inhibitor using ExPASy software. c Deduced hydrophobic index of Dolichos biflorus protease inhibitor protein using ProtScale package of the ExPASy web server 
Table 1 Amino acid composition of the Dolichos biflorus protease inhibitor protein encoded by the ORF of full-length gene sequence as determined by BioEdit software

\begin{tabular}{lrr}
\hline Amino acid & Number & Mol \% \\
\hline Ala A & 9 & 4.05 \\
Cys C & 5 & 2.25 \\
Asp D & 12 & 5.41 \\
Glu E & 9 & 4.05 \\
Phe F & 16 & 7.21 \\
Gly G & 23 & 10.36 \\
His H & 2 & 0.90 \\
Ile I & 15 & 6.76 \\
Lys K & 10 & 4.50 \\
Leu L & 24 & 10.81 \\
Met M & 2 & 0.90 \\
Asn N & 21 & 9.46 \\
Pro P & 11 & 4.95 \\
Gln Q & 3 & 1.35 \\
Arg R & 6 & 2.70 \\
Ser S & 16 & 7.21 \\
Thr T & 14 & 6.31 \\
Val V & 18 & 8.11 \\
Trp W & 1 & 0.45 \\
Tyr Y & 5 & 2.25 \\
\hline
\end{tabular}

\section{Results and discussion}

Southern blotting

The presence of protease inhibitor (PI) gene in Dolichos biflorus seedlings was confirmed by Southern blotting. Purified genomic DNA (10 mg) digested with EcoRI and BamHI appeared as a continuous smear on $0.8 \%$ agarose gel, indicating that the DNA had been restricted. Hybridization of the blot containing restricted DNA with radiolabeled chickpea TI probe revealed the presence of a DNA band of $1.5 \mathrm{~kb}$ (Fig. 1a), implying the presence of PI gene in D. biflorus seedlings. This observation suggested a considerable homology between chickpea and D. biflorus PI genes. Yoshiyuki et al. (2000) observed a single $2.5 \mathrm{kbp}$ fragment of PI gene in Southern blot analysis of soybean when EcoRI was used for restriction digestion. Natarajan et al. (2007) also observed single copy gene of Kunitz-type TI in all genotypes of soybean under study by DNA blot analysis.

\section{PCR amplification}

The screening of genomic or cDNA library by a DNA probe or antibody is quite time consuming and laborious; the PCR technique was used to directly amplify $D$. biflorus protease inhibitor (HGPI) DNA. PCR amplification reaction was done using the synthetic forward and reverse primers designed from the conserved region of PI gene of legumes. PCR was used to identify regions which were conserved and, therefore, may represent important functional domains. Out of the several primer combinations taken for the PCR, only one with forward primer $\left(5^{\prime}-\mathrm{AT}\right.$ GAAATCCATTGTATTCTTC- $\left.3^{\prime}\right)$ and reverse primer $\left(5^{\prime}\right.$ TTAAACTGACGCATCAAATCC- $3^{\prime}$ ) gave amplification product of the expected size, i.e., $\sim 700$ bp when run on $1.2 \%$ agarose gel (Fig. 1b). The PCR product was purified, ligated to pGEMT easy vector and transformed successfully. The transformants were selected on LA plates containing X-Gal, ampicillin and IPTG. The white colonies that appeared on the selection plate were employed for plasmid DNA isolation and restricted with EcoRI. The restricted samples were found to contain the insert ( 700 bp) when run on an agarose gel. Paralleled colony PCR product of $700 \mathrm{bp}$ was amplified with the same primers which coincided with the expected product size, confirming the presence of PI gene in D. biflorus. The positive clone was sequenced and the resulting sequence (Fig. 2) was analyzed using bioinformatics tools. Plant PI genes have earlier been isolated through a PCR-based method from various plants including Apios americana (Zhang et al. 2008), Solanum tuberosum (Valueva et al. 2008) and soybean (Gao et al. 1998).

In silico analysis of the isolated gene sequence

Internet bioinformatic resources and computer simulation analysis were used to study the DNA sequence. The nucleotide sequence obtained was analyzed on URL http://www.ncbi.nlm.nih.gov. BLASTN search analysis of the sequence on URL http://blast.ncbi.nlm.nih.gov/Blast. cgi showed $100 \%$ coverage with Cicer arietinum trypsin inhibitor mRNA (Accession No. AJ276262.1). It also showed significant homologies with Cajanus cajan protease inhibitor (GU320336.1), Medicago truncatula proteinase inhibitor (AF526372.1), Glycine max trypsin inhibitor mRNA (EU444603.1) and with other sequences. This indicated that the isolated PI gene belonged to the legume PI gene family.

The PCR fragment encompassed the open reading frame of 669 bp encoding a HGPI precursor with 222 amino acid residues (indicated by one letter code, Fig. 2) as predicted by FGENESH program of Softberry web server. Similar values of open reading frame encoding PI have been reported from other legumes, viz., soybean C-II protease inhibitor gene with 645 bp (Jourdrier et al. 1987), cowpea trypsin inhibitor mRNA with 583 bp (Hilder et al. 1989), cowpea trypsin inhibitor gene with 504 bp (Lawrence et al. 
(a)

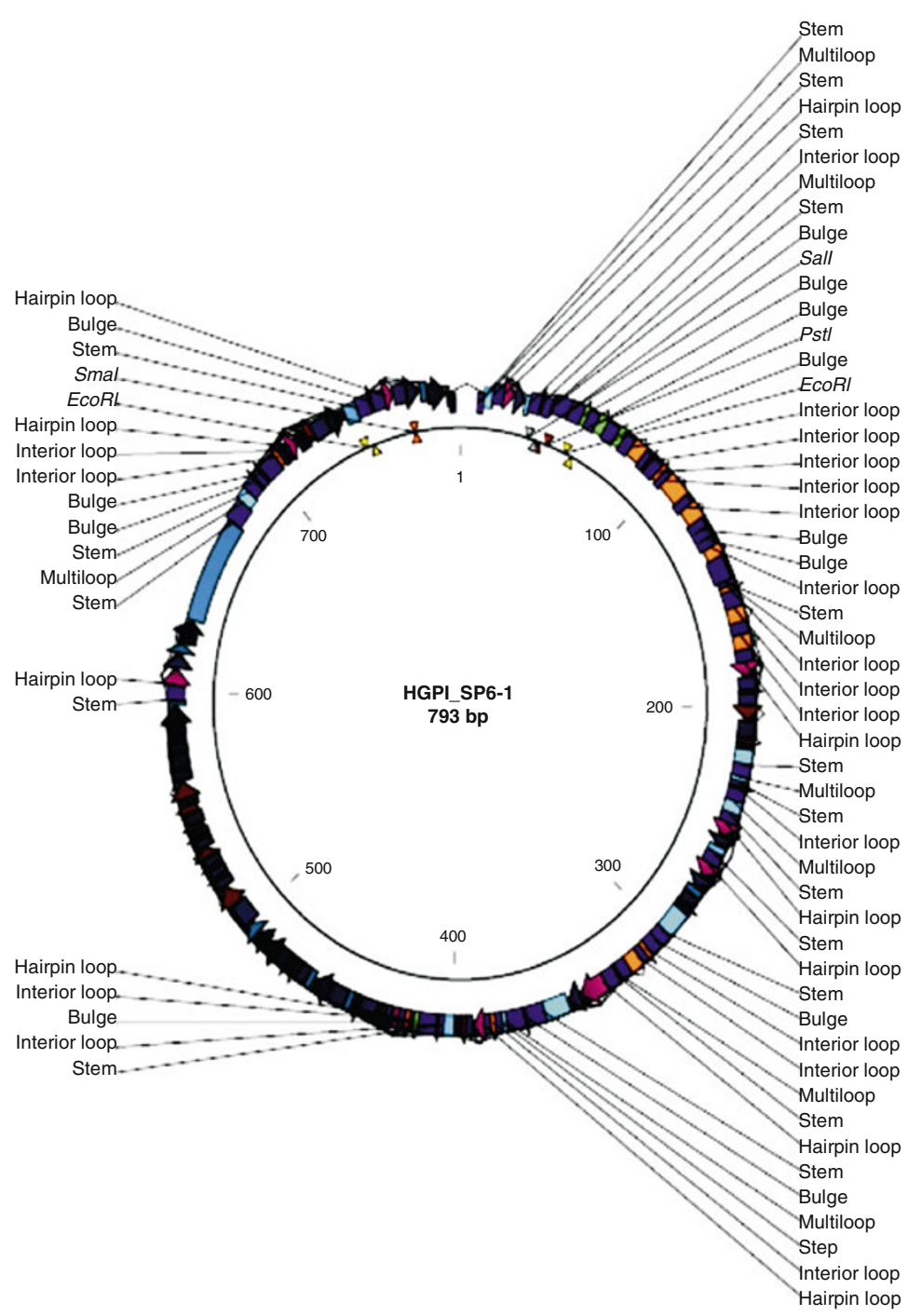

(b)
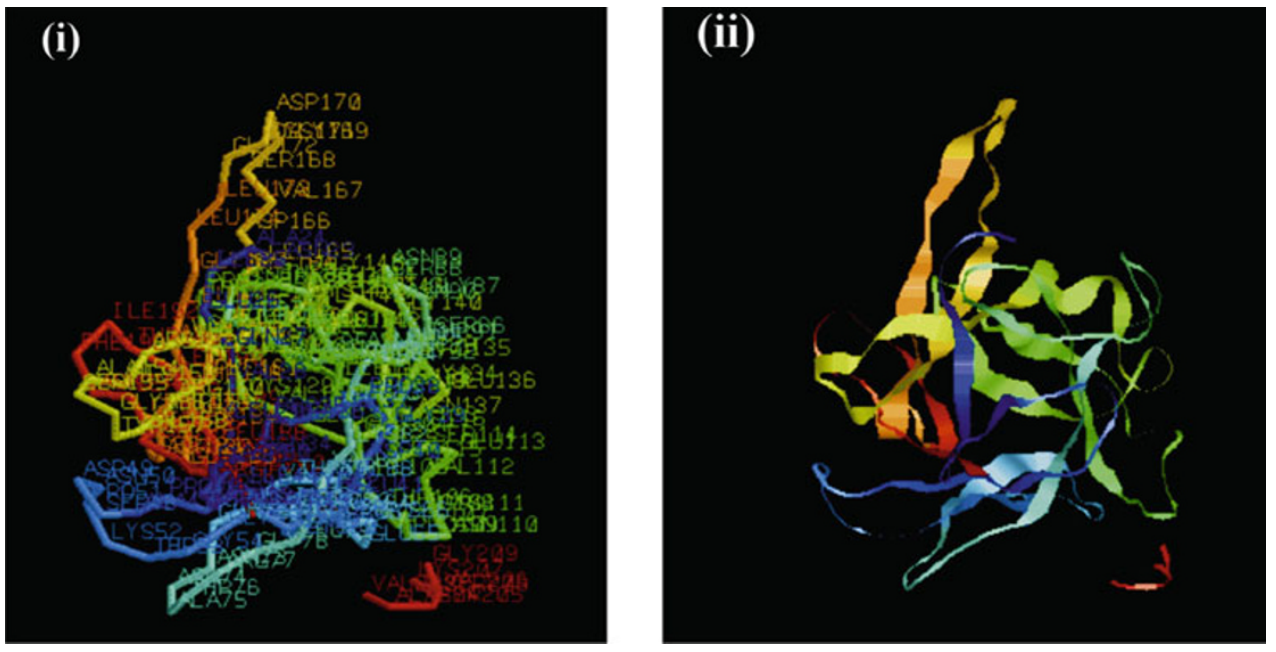

Fig. 4 a Prediction of secondary structure of Dolichos biflorus protease inhibitor protein. b Three-dimensional representation of the Dolichos biflorus PI using software 3Djigsaw $i$ labeled backbone form, ii ribbon form 
Fig. 5 a Alignment of deduced amino acid sequence of Dolichos biflorus PI gene with other legume PIs CAB76906.1 from Cicer arietinum, ADB44827.1 from Cajanus cajan, ACA23207.1 from Glycine max and O82711.1 from Pisum sativum.

b Phylogenetic tree analysis of Dolichos biflorus protease inhibitor (HGPI) with other legume PIs encoding Kunitztype PIs CAB76906.1 from Cicer arietinum, ADB44827.1 from Cajanus cajan, AAM88404.1 from Medicago truncatula, 1R8N from Delonix regia, ACF74332.1 from Arachis hypogea, CAI77803.1 from Populus tremula, ACC66059.1 from Raphanus sativus, O82711.1 from Pisum sativum and ACA23207.1 from Glycine max
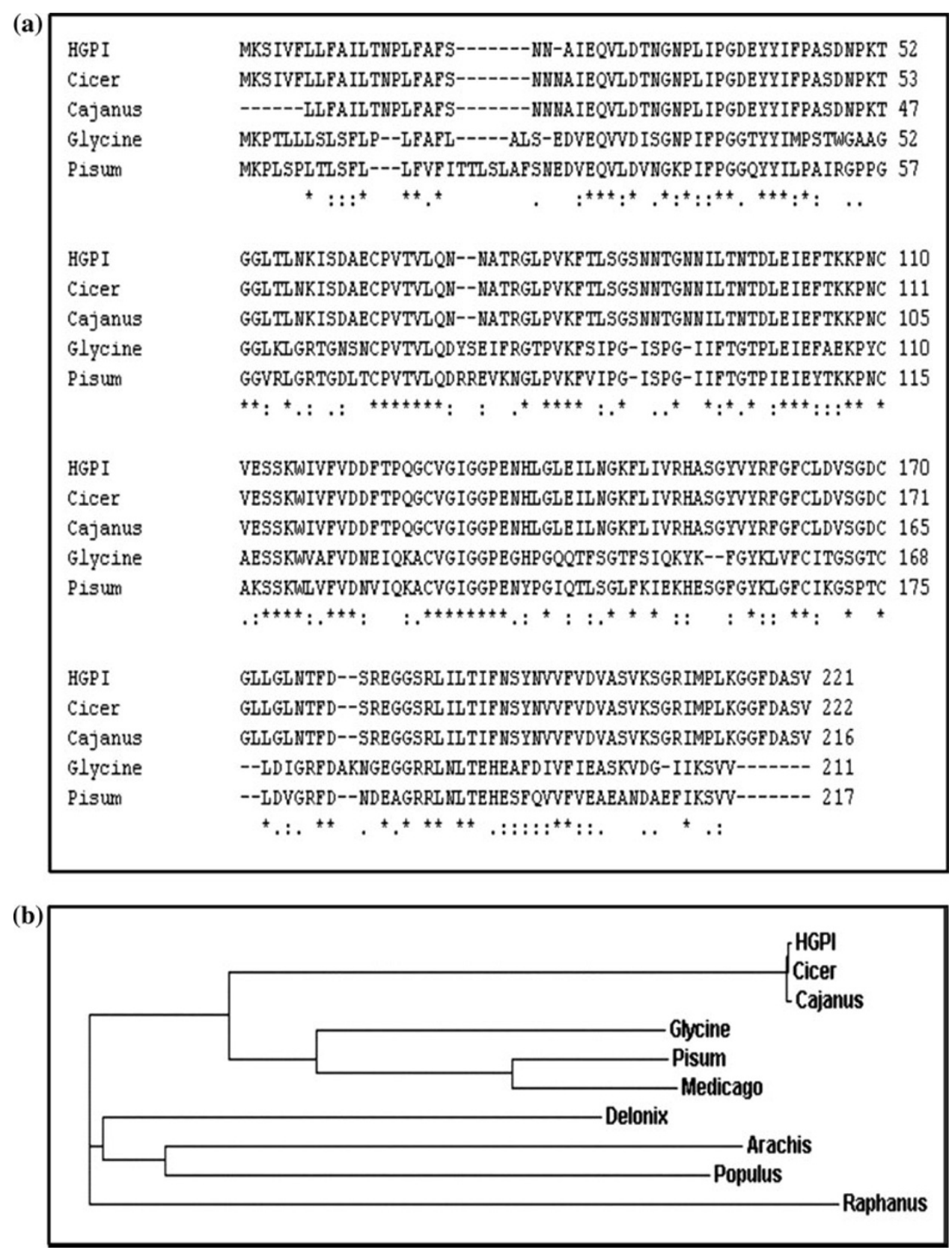

2001) and soybean Kunitz trypsin inhibitor gene with 663 bp (Gao et al. 1998). The sequence did not contain introns. These results were in accordance with the previous reports of intron less PI genes (Wang et al. 2008; Yoshiyuki et al. 2000). In contrast, Ceci et al. (1995) reported that the gene coding for the mustard trypsin inhibitor-2 was discontinuous, being interrupted by a 193-bp long intron.

The deduced MW of the sequence was 4,04,363 Da for double strand with $34.58 \%(\mathrm{G}+\mathrm{C})$ and $65.42 \%(\mathrm{~A}+\mathrm{T})$ content, which was done using the BioEdit software. Therefore, based on the nucleotide composition, it was clear that the isolated sequence encoding for PI protein was AT rich, similar to that reported by Lawrence et al. (2001) in cowpea trypsin inhibitor mRNA. Restriction map analysis of PI sequence generated using software available at http://www.nebcutter.com indicated that the sequence did not carry restriction sites for the widely used restriction enzymes such as BamHI, EcoRI, EcoRV, HindIII, HpaI, NcoI, NotI, PstI, SacI, SalI, SmaI, XbaI, XhoI and XmnI (Fig. 3a). To release the PI sequence from the clone, EcoRI and NotI enzymes were chosen as they were present at the flanking sites at multiple cloning sites (MCS) region and not internally in the ORF.

The deduced $D$. biflorus PI amino acid sequence used as a query sequence in a BlastP search showed the top scoring results with Kunitz proteinase inhibitor (Cicer arietinum), 
protease inhibitor (Cajanus cajan), Kunitz trypsin protease inhibitor (Glycine max) and so on. This was a very interesting finding of the present study, in that the isolated gene showed homology with Kunitz-type inhibitor, which had not been reported earlier in this crop, although the Bowman-Birk inhibitor gene had already been reported from $D$. biflorus (AM494004).

The protein was found to be rich in glycine, leucine, asparagine, serine and valine as deduced by the BioEdit software (Table 1). A signal peptide of 18 amino acids at the N-terminal end with a cleavage site between amino acid 18 and 19 was presumed by SignalP 3.0 server on the ExPASy web server (Fig. 3b), which were involved in the targeting of proteins to specific compartment as has been reported in many protease inhibitors such as soybean (Hammond et al. 1984), cowpea (Hilder et al. 1989) and pea (Domoney et al. 1995). Since the available evidence from other legumes indicated that PIs were primarily cytosolic proteins, no signals should be necessary. So far, the exact function of signal peptide sequence in the PI could not be assigned (Hilder et al. 1989). Analysis of the predicted $D$. biflorus PI protein sequence by TargetP 1.1 server revealed a secretion pathway score of 0.965 , indicating that the inhibitor was likely to be secreted on the outside of the cell.

The whole protein and atomic composition analysis of PI was done by BioEdit Software. ProtParam package of the ExPASy web server computed various physical and chemical parameters of PI protein. The predicted MW of the PI protein was $\sim 24 \mathrm{kDa}$, of which 21 were negatively charged and 16 were positively charged residues with a theoretical pI of 5.0. This value of MW falls within the range reported previously for Kunitz-type trypsin inhibitor (Lingaraju and Gowda 2008; Oliveira et al. 2007). The total number of atoms present in the protein was 3,374, and the extinction coefficient was $13,200 \mathrm{M}^{-1} \mathrm{~cm}^{-1}$. The instability index depicted a value of 29.45 , which suggested the stable nature of this protein. The aliphatic index of this protein was 96.08, while the grand average of hydropathicity was 0.112 , confirming the hydrophilic nature of the inhibitor as predicted by the BioEdit software.

The exact mass of the D. biflorus PI was deduced using the Isotopident package of the ExPASy web server. The mono-isotopic mass and the exact mass calculated were 23,981.184 and 23,993.218 Da, respectively. The most likely combination of isotopes was $13.75 \%$ and thus the mass of this protein in round figure was 23,981 amu. The hydropathy index deduced using BioEdit Software predicted a hydrophilic nature of this inhibitor and such hydrophilic sequence suggested a cytosolic/extracellular nature of this inhibitor (Fig. 3c). The secondary structure (Fig. 4a) and three-dimensional structure (Fig. 4b) of the D. biflorus PI has been predicted. ClustalW analysis using
BioEdit software on $D$. biflorus calculated the best match for the D. biflorus PI with other PI sequence encoding Kunitz-type trypsin inhibitor available on NCBI gene bank and lined them to identify their similarities and differences (Fig. 5a). A dendrogram displaying phylogenetic relationship showed comparisons of PI sequences encoding Kunitz-type inhibitor in several plants, indicating that TIs from Cicer arietinum and Cajanus cajan have the closest relationships with $D$. biflorus PI sequence (Fig. 5b). This might be due to the presence of both Kunitz and BowmanBirk type PIs in these crops. The result was in line with that obtained in BlastP analysis.

Expression analysis of the isolated protease inhibitor gene

The expression of PI was analyzed in different tissues of $D$. biflorus viz., leaves, roots, stems, pod wall, flowers, seedlings and seeds by RT-PCR. The size of the cDNA synthesized ranged from $100 \mathrm{bp}$ to $3 \mathrm{~kb}$, which indicated the intactness of mRNA with minimal degradation. The cDNA reverse transcribed from RNA was subjected to PCR amplification using PI gene-specific primers, which were expected to give an amplicon of $\sim 700 \mathrm{bp}$. Hence, the presence of $\sim 700 \mathrm{bp}$ amplicon would indicate the expression of PI gene in the tissue. In the present study, $700 \mathrm{bp}$ amplicon was observed in all the tissues viz., leaves, roots, stems, pod wall, flowers, seedlings and seeds of D. biflorus, but with differing intensities (Fig. 6a). Simultaneously, parallel PCR was run using primers of housekeeping actin gene as internal control (Fig. 6b). As

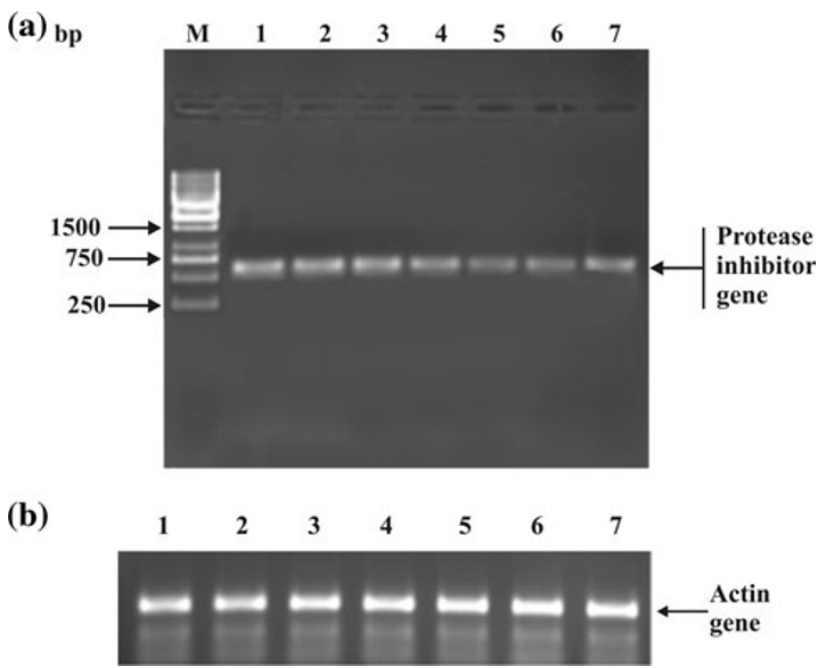

Fig. 6 a Expression analysis of protease inhibitor in different tissues of Dolichos biflorus. Lane M 100 bp DNA ladder, Lanes 1-7 total RNA from 1 seeds, 2 leaves, 3 roots, 4 stems, 5 flowers, 6 pod wall and 7 seedlings. b PCR amplification using primers of housekeeping actin gene in different tissues of Dolichos biflorus. Lanes 1-7 total RNA from 1 seeds, 2 leaves, 3 roots, 4 stems, 5 flowers, 6 pod wall and 7 seedlings 
the PI mRNA was detected in all the tested plant tissues, the $D$. biflorus PI gene was likely to be expressed constitutively. The constitutive expression of PI gene has also been observed by other researchers (Kim et al. 2009; Zhang et al. 2004). The same size of the amplified product from genomic as well as cDNA suggested that D. biflorus PI gene may not contain an intron. This was further evident from in silico studies of the PI gene. The physiological functions of PIs were indicated to be mainly based on reports of their developmental and tissue-specific expression patterns (Botella et al. 1996). Expression analysis of this gene will provide fundamental information to facilitate their manipulation as a source of insect resistance in the development of transgenic plants.

\section{Conclusion}

A novel full-length Kunitz-type trypsin inhibitor gene was isolated from $D$. biflorus using a PCR-based method. The gene was further characterized using bioinformatics tools. RT-PCR analysis revealed constitutive expression of the PI gene in different tissues of $D$. biflorus. Based on preliminary experiments in which the $D$. biflorus PI protein was found to exhibit antifeedant and anti-fungal activity, it could be inferred that the gene isolated from this crop could be exploited for generating transgenic plants, effective against insects and pathogen.

Acknowledgments The first author acknowledges Kurukshetra University, Kurukshetra, India for awarding university research fellowship. This work was a part of a research project fund no. ERIP/ ER/0703612/M/01/1056.

Open Access This article is distributed under the terms of the Creative Commons Attribution License which permits any use, distribution, and reproduction in any medium, provided the original author(s) and the source are credited.

\section{References}

Beuning LL, Spriggs TW, Christeller JT (1994) Evolution of the proteinase inhibitor I family and apparent lack of hypervariability in the proteinase contact loop. J Mol Evol 39:644-654

Botella MA, Xu Y, Prabha TN, Zhao Y, Narasimhan ML, Wilson KA et al (1996) Differential expression of soybean cysteine proteinase inhibitor genes during development and in response to wounding and methyl jasmonate. Plant Physiol 112:1201-1210

Brattsten LB (1991) Bioengineering of crop plants and resistant biotype evolution in insects: counteracting coevolution. Arch Insect Biochem Physiol 17:253-267

Ceci LR, Spoto N, de Virgilio M, Gallerani R (1995) The gene coding for the mustard trypsin inhibitor-2 is discontinuous and wound inducible. FEBS Lett 364:179-181

Domoney C, Welham T, Sidebottom C, Firmin JL (1995) Multiple isoforms of Pisum trypsin inhibitors results from modification of two primary gene products. FEBS Lett 360:15-20
Gao YF, Zhu Z, Xiao GF, Zhu Y, Wu Q, Li XH (1998) Isolation of soybean Kunitz trypsin inhibitor gene and its application in plant insect resistant genetic engineering. Acta Bot Sin 40(5):405-411

Goldberg RB, Barker SJ, Perez-Grau L (1989) Regulation of gene expression during plant embryogenesis. Cell 56:149-160

Hammond RW, Foard DE, Larkins BA (1984) Molecular cloning and analysis of a gene coding for the Bowman-Birk protease inhibitor in soybean. J Biol Chem 259:9883-9890

Hilder VA, Barker RF, Samour RA, Gatehouse AMR, Gatehouse JA, Boulter D (1989) Protein and cDNA sequences of Bowman-Birk protease inhibitors from the cowpea (Vigna unguiculata Walp). Plant Mol Biol 13(6):701-710

Hilder V, Gatehouse A, Boulter D (1993) Transgenic plants countering insect tolerance: protease inhibitor approach. In: Kung S, Wu R (eds) Transgenic plants. Academic Press, London, pp 317-338

Ismanizan I, Fong SL, Ruslan A, Chan KF, Zamri Z, Nik MS et al (2010) Molecular and expression analysis of cowpea trypsin inhibitor (CpTI) gene in transgenic Elaeis guineensis Jacq leaves. Aust J Crop Sci 4(1):37-48

Johnson R, Narvaez J, An G, Ryan CA (1989) Expression of proteinase inhibitors I and II in transgenic tobacco plants: effects on natural defense against Manduca sexta. Proc Natl Acad Sci USA 86:9871-9875

Jourdrier PE, Foard DE, Floener LA, Larkins BA (1987) Isolation and sequence of cDNA encoding the soybean protease inhibitor P I, IV and C-II. Plant Mol Biol 10:35-42

Kansal R, Kuhar K, Verma I, Gupta RN, Gupta VK, Koundal KR (2008) Improved and convenient method of RNA isolation from polyphenols and polysaccharide rich plant tissues. Indian J Exp Biol 47:842-845

Kim JY, Park SC, Kim MH, Lim HT, Park Y, Hahm KS (2005) Antimicrobial activity studies on a trypsin-chymotrypsin protease inhibitor obtained from potato. Biochem Biophys Res Commun 330:921-927

Kim J, Baek S, Im K (2009) Overexpression of a Kunitz-type trypsin inhibitor (AtKTI) causes early flowering in Arabidopsis. Plant Growth Regul 59(1):75-81

Lawrence PK, Nirmala J, Koundal KR (2001) Nucleotide sequence of a genomic clone encoding a cowpea (Vigna unguiculata L.) trypsin inhibitor. Electron J Biotechnol 4(1):46-51

Lingaraju MH, Gowda LR (2008) A Kunitz trypsin inhibitor of Entada scandens seeds: another member with single disulfide bridge. Biochim Biophys Acta 1784(5):850-855

Lingling L, Lei J, Song M, Li L, Cao B (2005) Study on transformation of cowpea trypsin inhibitor gene into cauliflower (Brassica oleracea L. var. botrytis). Afr J Biotechnol 4(1):45-49

Major IT, Constabel CP (2006) Molecular analysis of poplar defense against herbivory: comparison of wound- and insect elicitorinduced gene expression. New Phytol 172:617-635

Mehta SL, Simlot MM (1982) An acid stable trypsin-chymotrypsin inhibitor from horse gram (Dolichos biflorus). J Biosci 4(3): 295-306

Menke FLH, Kijne JW, Memelink J (1996) Digging for gene expression levels in Catharanthus roseus: nonradioactive detection of plant mRNA levels. In: Leous M, Matter K, Schröder C, Ziebolz B (eds) Biochemica 2. Boehringer-Mannheim, Mannheim, pp 16-18

Murray MG, Thompson WF (1980) Rapid isolation of high molecular weight plant DNA. Nucleic Acids Res 8:4321-4325

Natarajan S, Xu C, Bae H, Bailey BA (2007) Proteomic and genomic characterization of Kunitz trypsin inhibitors in wild and cultivated soybean genotypes. J Plant Physiol 164(6):756-763

Odani S, Ikenaka T (1976) The amino acid sequences of two soybean double-headed proteinase inhibitors and evolutionary consideration on the legume proteinase inhibitors. J Birches 80:641-643 
Oliveira AS, Migliolo L, Aquino RO, Ribeiro JKC, Macedo LLP, Andrade LBS et al (2007) Purification and characterization of a trypsin-papain inhibitor from Pithecelobium dumosum seeds and its in vitro effects towards digestive enzymes from insect pests. Plant Physiol Biochem 45(10-11):858-865

Orf JH, Hymowitz T (1979) Genetics of the Kunitz trypsin inhibitor. An antinutritional factor in soybeans. J Am Oil Chem Soc 56: 722-726

Park Y, Choi BH, Kwak JS, Kang CW, Lim HT, Cheong HS et al (2005) Kunitz-type serine protease inhibitor from potato (Solanum tuberosum L. cv. Jopung). J Agric Food Chem 53:64916496

Pujol M, Hernandez CA, Armas R, Coll Y, Alfonso-Rubi J, Perez M et al (2005) Inhibition of Heliothis virescens larvae growth in transgenic tobacco plants expressing cowpea trypsin inhibitor. Biotechnol Appl 22:127-130

Qu LJ, Chen J, Liu MH, Pan NS, Okamoto H, Lin ZZ et al (2003) Molecular cloning and functional analysis of a novel type of Bowman-Birk inhibitor gene family in rice. Plant Physiol 133:560-570

Quilis J, Meynard D, Vila L, Aviles FX, Guiderdoni E, Segundo BS (2007) A potato carboxypeptidase inhibitor gene provides pathogen resistance in transgenic rice. Plant Biotechnol J 5(4): $537-553$

Ryan CA (1990) Proteinase inhibitors in plants: genes for improving defenses against insects and pathogens. Annu Rev Phytopathol 28:425-449

Sambrook J, Russel DW (2001) Molecular cloning: a laboratory manual, 3rd edn. Cold Spring Harbor Laboratory Press, New York

Sambrook J, Fritsch EF, Maniatis T (1989) Molecular cloning: a laboratory manual. Cold Spring Harbor Laboratory Press, New York

Sardana RK, Ganz PR, Dudani AK, Tackaberry ES, Cheng X, Altosaar I (1998) Synthesis of recombinant human cytokine
GMCSF in the seeds of transgenic tobacco plants. In: Cunningham C, Porter AJR (eds) Recombinant proteins from plants production and isolation of clinically useful compounds. Humana Press, Totowa, pp 77-87

Southern E (1975) Detection of specific sequences among DNA fragments separated by gel electrophoresis. J Mol Biol 98: 503-507

Sreerama YN, Das JR, Rao DR, Gowda LR (1997) Double-headed trypsin/chymotrypsin inhibitors from horse gram (Dolichos biflorus): purification, molecular and kinetic properties. J Food Biochem 21:461-477

Thompson JD, Higgins DG, Gibson TJ, Clustal W (1994) Improving the sensitivity of progressive multiple sequence alignment through sequence weighting, positions-specific gap penalties and weight matrix choice. Nucleic Acids Res 22:4673-4680

Valueva TA, Speranskaya AS, Revina TA, Shevelev AB (2008) Molecular cloning and expression of genes of Kunitz-type C protease inhibitors from potato. Russ J Bioorg Chem 34(3): 310-317

Wang YP, Chen XT, Qiu LJ (2008) Novel alleles among soybean Bowman-Birk proteinase inhibitor gene families. Sci China Ser C Life Sci 51(8):687-692

Yoshiyuki A, Matsushima A, Tsuru Y, Hirota T, Hirata T (2000) Isolation and sequencing of a cDNA clone encoding a $20-\mathrm{kDa}$ protein with trypsin inhibitory activity. Biosci Biotechnol Biochem 64(6):1305-1309

Zhang HY, Xie XZ, Xu YZ, Wu NH (2004) Isolation and functional assessment of a tomato proteinase inhibitor II gene. Plant Physiol Biochem 42(5):437-444

Zhang Y, Kouzuma Y, Miyaji T, Yonekura M (2008) Purification, characterization and cDNA cloning of a Bowman-Birk type trypsin inhibitor from Apios americana Medikus tubers. Biosci Biotechnol Biochem 72(1):171-178 